\title{
THE PHANTOM LIMB FEELING AND THE BODY SCHEME. A STUDY ON THE REGRESSION OF THE PHANTOM LIMB
}

\author{
MANFRED IN DER BEeCK *
}

Most people who have suffered amputations feel the missing limb for some considerable time, as though it were still present: this is the socalled phantom limb feeling. Its origin is as yet unexplained. In the case of amputations in peace-time it often lasts for only a few days or weeks, whereas, when amputations are carried out under war-time conditions, the feeling of the phantom limb, or the hallucinatory feeling of pain, may last from the moment of the amputation onwards, and its regression is often very slow. By way of analogy one may mention the comparative rarity of causalgias after injuries to nerves in peace-time, as contrasted with the more frequent occurrence of causalgic conditions where wounds take place during war. It may be that the state of vegetative excitation of the amputated persons at the moment of the wounding may have some influence on the origination of the hallucinatory pains. A long period in hospital, often with continuous suppurations, the occurrence of a neuroma, a pressure on the scars, or acanthopelvic formations, are also possible originating causes. The effect of the hallucinatory pains is that the feeling of the amputated person for his phantom limb remains particularly vivid in his consciousness. If there are no hallucinatory pains, then in many cases the sensation of the phantom limb is scarcely felt, or is not felt at all.

During investigations which were made of 75 cases of persons am. putated during the second world war it was noticed that many of the affected persons had never thought of their phantom limb. They only became acquainted with the feeling for their phantom as the result of the close and intensive investigation. Some of them were surprised at the large number of sensory impressions which were brought to light. Others said that they had deliberately excluded or "repressed" these perceptions, as being a disturbing influence for their future life. The descriptions of the phantom feeling differed in degree of completeness according to the intensity of the sensations and the extent of self-observation. Amputated persons of low intelligence could give only less complete descriptions of the phantom feeling.

The phantom limb was most often described in one stereotyped posi. tion. It was mostly felt in the position of the leg or arm at the moment

* Dr. med., Dr. phil. Provinzial-Heilanstalt (Niedermarsberg, Germany).

Author's Note - Translated from the Germany by: Patria Translation Bureau; 6, Central Chambers; Hendon, London, $\mathrm{NW}^{4}$. 
of the wounding, for instance, with knee drawn up, or with foot in the taking-off position at the moment of jumping up. There were also a number of descriptions which mentioned the position of the leg as fixed in the plaster splint before the amputation. Where extension bandages were described, the extensory wire was particularly felt in the phantom limb as "piercing the bone". Persons whose arm had been amputated said that they felt this limb in the form of the abduction splint. Toes and fingers were often in positions which were felt as unpleasantly cramped, or in clutching attitudes.

About three-quarters of the amputated persons whose cases were examined felt the distal extremities most clearly. The toes and fingers, the basal foot joint and the wrist were felt more acutely than the knee and the calf, or the lower arm and the elbow. The ability to move the small joints of toes and fingers could be felt more clearly than the knee or elbow joint. As the phantom limb feeling declined in intensity, it was the proximal parts of the limb which first disappeared.

Some of these experiences do not correspond with the results of earlier investigations. The observations reported by other authors refer only to individual cases. The phenomenon of the phantom feeling as such has of course not yet been the object of a special investigation on a large scale, in so far as can be judged on the basis of the available literature.

Even in the case of the observations available, which were collected as part of a larger research that has been carried out on the problem of amputated persons, special attention only began to be paid to thoroughly investigating the phantom feeling when it was discovered that the facts found were at variance, and even in contradiction, with the earlier data.

For instance Ach, in his basic work "Zur Psychologie der Amputierten", described a person whose upper arm had been amputated, and who could move his phantom lower arm better than his fingers. Altstaedt, it is true, said that the distally situated parts were more clearly felt, but that the proximal parts also remained present in the conșciousness. Recently Skalweit also declared his adherence to this view. In many cases it was stated that the distal parts of the limb gradually approached the proximal stump (Paré, Pick,- quoting from Kratzberg). A patient of Schilder had the feeling as though his toes were located immediately at the end of the stump; another patient reported that his amputated hand, in its normal size, was approaching the stump (quotation from Frick and von Angyal). Many writers have mentioned the diminution in size, or the so-called regression, of the phantom limb (for instance Klein).

I have also observed a diminution of the phantom limb in the sense of the gradual disappearance of the parts close to the stump. In no case however have I been able to observe the parts of the limb distant from the trunk approaching the end of the stump.

The connection between the weather, as felt by the sufferer, and the phantom experience has often been of some importance. It was last 
mentioned by Kampik and Reiter, without their giving any description of it. Accordingly, in the following literal reproduction of the description of phantom feelings given by a man who had suffered a double amputation (one of the cases investigated by me, to support the observations), the perceptions of the weather may be regarded as an additional point estab. lished:

"I was wounded in the left thigh on 31 st May, 1942 by a shell splinter. It was a flesh wound. On account of gas gangrene in the left lower leg amputation was carried out on 20th June, 1942 in the upper third of the left thigh. Immediately after the amputation I felt the left leg throughout its whole length. The doctor in charge of the case said that this would disappear in the course of weeks. 'There was no pain; it was a prickling sensation, as though the leg were hanging down with the hollow of the knee on one edge of the bed. It was an itching, furry feeling, a continual to-ing and fro-ing, which was felt more keenly during the passing of water or action of the bowels. The whole leg was curled up in the sitting position, and when standing it was braced up straight.

"Whenever the weather changes, I have the feeling as though the toe-nails are being pulled upwards; this begins two or three days beforehand. The thunderstorm on 5th June, 1947 was felt by me a whole two days earlier. The pulling at the nails continued until the storm came. When the strong wind began to blow and the first heavy raindrops fell, the thing became easier to bear, but still continued for a number of hours. I did not feel well again until the wind had completely dropped.

"I can move the toes best, both upwards and sideways. When it is raining, the toes rise up of themselves, but do not go down again without my will. I always have to push them down again first. If I did not do that, they would remain standing up. 'That gives a feeling of cramp and causes me trouble, and that is why I always have to push them down. I can move the ankle joint to the left and to the right. It does not move by itself, but only when I wish. I can tighten the muscles of the calf. I hardly notice my left knee any more now, nor can I make any movement now in the knee joint. At the beginning I felt it more clearly, and could also move it. Only from time to time it is as if I could feel the knee-cap a little.

"My right ankle was smashed by the same shell splinter. The amputation of the right lower leg was carried out on 28th September, 1942. Before the amputation there were great pains in the ankle-joint and on the outside of the upper part of the foot. These pains continued after the amputation exactly as before. In $\mathrm{my}$ right ankle $\mathrm{I}$ have a continual fiercing feeling, as if there were a knife stuck in it and always being turned round. In this spot I had in 1941 a perforating wound from an infantry gun shell.

"I feel changes in the weather more on the right side than on the left. It is as if my right foot had been plunged into hot water, and I pulled it out suddenly and it hurt all over; or it is a feeling as if the leg were being squeened in a pair of pincers, or were lying under a weight. At the same time the piercing feeling in the right ankle becomes keener. 'The pains are so strong, on the right side, that I should say they were about ten times as great. On the other hand the left leg only feels as though it had gone to sleep. If I get particularly violent pain in the right foot, particularly on the outer edge of the foot, then it is for the moment as though there were a reflection of it, which can be felt in just the same way on the left side, but in a much weaker form.

"Ihe toes rise up, but on this side they go down again of themselves. By my own will I can still spread them out, on the right side. On the left side I cannot do this very well any more, and if I do I have trouble in getting them together again. I can turn the foot to the left and to the right, and also downwards. The amputated lower leg is always in the position corresponding to the 
attitude of the trunk and body. On the whole, the feelings and the pains in both legs are becoming constantly weaker and weaker".

Further descriptions must be omitted for lack of space. The case material is published in detail in the book.

For the purpose of explaining the hallucinatory perception, the term "body scheme" has been coined. According to this concept, the phantom limb feeling is the realisation of the accustomed body space-picture which remains after the amputation. According to the definition of Schilder, the body scheme is a spatial picture formed from the patient's own body. According to Head, the spatial impressions form organised models of ourselves, which are called body schemes. Benedeck and von Angyal define the body scheme as a potentially organised functional complex. which is produced by the cortical energetic changes, that proceed by way of centripetal projections of the functional and static excitations of the organism. In Conrad's view, the body scheme represents the consciousness of the patient's own body in the "gestalt" or psychological-engram sense. as an entity divorced from the space-perception and action-perception. Jaspers assumes that the hallucinatory perception is subject to localisation in the cortex, since Head, when a corresponding injury to the cortex took place, found that the existing phantom limb disappeared.

This short summary of definitions may suffice. The fact that a spatial picture of one's. own organism exists is known to everybody from his experience. The amputated person can become more clearly conscious of this picture through his experience of the phantom. limb?

What explanation can now be given of the regression of the phantom

In this connection, regression should not be taken to mean a diminution of the phantom limb as a whole, or a fading out of the proximal parts of the limb, together with the feeling that the distal parts are approaching the stump; it means the fact of the fading out, to a constantly increasing extent, of the proximal parts of the phantom limb in the following order: knee, calf, foot, toes, or elbow, lower arm, wrist, middle hand, fingers.

Katz explains this regression by saying that the body scheme of the adult is gradually replaced, as regards the amputated limb, by the more resistent body scheme of the child. Schilder also inclines to this conception. Reference to the tenacity of the traces of childish memories is also made by Benedek and von Angyal. These authors assign special importance to certain experiences of strongly affective content, such as the position of the leg as felt at the moment of wounding, the paint of gunshot wounds and the like, which are important in the later history of the limb. According to their conception of the body scheme, they regard memories of this type as among the stable factors. Apart from this they state that, during the regression of the phantom limb, the less stable portions of the body scheme, which usually means the proximal parts of the limbs. are the first to suffer and to fade out in accordance with the biological and individual importance of the part of the body concerned. Conrad also 
expresses the view in very general terms, in this otherwise very accurate and critical study, that the most plausible explanation of the relatively frequent statement that an upper extremity has grown shorter is to be found in the fact that, in the patient's perceptions, the feeling surfaces of the hands are much closer than for instance the lower arms. He there. fore localises them, by a kind of deliberate act, in the elbows or shoulders.

When it is sought to explain the regression of the phantom limb, that is, the disappearance of the proximal parts of the limbs before the distal parts, there are indications of close psycho-physical connections. Wernicke used the term "Somatopsyche" to describe the interplay of the consciousness of bodily conditions and the spatial body scheme. The consciousness which the organism has of its condition is built up by means of the specific mental sensations, which can be physiologically classified. For the characteristics of the phantom feeling, bodily sensations are important. They can be classified into the sensations of the surface of the body, of the position in space, and the patient's own movement. The sensations of the organs, through which the condition of the internal organs becomes noticeable, may be left out of account, as may also be sensations which originate through the eye and ear, as well as through the senses of smell and of taste. The physiological basis of the bodily sensations is to be found in the nervous sensory receptors of the very finely fissurated ends of the peripheral nerves.

The nerve ends, for pressure and touch, are the Meissner palpator corpuscles. They are not important only for tactile sensations, but play a major part in the perception and control of the position and movement of the limbe and joints. In addition, through the tangential increase or decrease of tension of the skin, they serve as contact-receptors. The nerveend organs of the sense of touch are almost at their thickest at the finger tip. The shortest distance apart for two clearly distinguishable sensations. the "threshold of simultaneous perception"; according to Rein amounts to $2 \mathrm{~mm}$ at the finger tip, but to $40 \mathrm{~mm}$ on the lower arm. A similar relationship is given by counting the Ruffini warmth-receptors. On the lower arm there are $0.3 \mathrm{sq} . \mathrm{cm}$, on the lateral surface of the fingers 2 sq. $\mathrm{cm}$. On the thigh, according to Rein, two simultaneously applied heatexcitations at distances of 20 to $30 \mathrm{~cm}$ apart can in some cases not be recognised as separate excitations. The receptors for the position and location of the extremities, if only on account of the number of joints in the hand and the foot, are much more numerous than in the case of the arm or leg.

This glance at the physiological characteristics of the sensitive nerveends shows that, before the amputation of a limb, the greatest number of the excitations felt is perceived through receptors in the distal extremities. The various excitations of the nerve-ends are conveyed, along the proper centripetal channels, to the ascending parietal convolution (gyrus postcentralis), and from there are absorbed into the body scheme as a part of the consciousness. After the loss of the extremity there is not merely 
an organic defect, but in addition a change gradually takes place in the body scheme. The loss of a limb is at first not noticed, is not believed to be true. In the place of the extremity there appears a phantom limb. Thus the missing limb continues to be perceived. Post-traumatically, it is only in the course of years that the consistency of arrangement and symmetry can no longer be maintained, as, through the absence of fresh perceptible centripetal excitations, the phantom limb feeling is forgotten".

The first to fade are the proximal parts of the limb. The distal parts of the phantom limb, which were more strongly engrammatised in proportion as the pre-traumatic sensory perceptions were more frequent and more intense, are more deeply anchored in the body scheme and remain in existence longer. Those memories which are charged with particularly strong emotional content, such as the position of the limb at the moment of wounding, or a "continual piercing feeling in the ankle" from an earlier perforating wound, are for the same reason also found for a longer time in the accounts of experience of the phantom limb.

Amputated persons in their twenties felt their phantom limb less clearly, and the proximal fading was quicker, than in the case of amputated persons over forty years of age. The receptors of the older amputated persons, whether haptic, thermic, hygric or kinesthetic, had pre-traumatically absorbed and conveyed to the centre more than twice the same quantity of excitations. Therefore in the case of such persons the body scheme is manifested in a more intense manner, and their feeling for the phantom limb as a whole remains in existence, while its distal parts in particular persist.

These observations may be taken as evidence in support of the explanation given for the regression of the phantom limb.

\section{BIBLIOGRAPHY}

1. Ach, H. - Kur Psychologie der Amputierten. Ein Beitrag zur praktischen Psychologie. Wilh. Engelmann, I.eipzig, 1920. 2. Altstaedt, R. -- Nervöse und psychische Störungen als Spätfolgen von Amputationem. Diss. Berlin, 1944. 3 von Angyal, I. and Benedek, L. - Monatschr. f. Psychiat. u. Neurol., 101, 1939. 4. Conrad, K. -- Das Körperschema. Ztschr. f. d. ges. Neurol. u. Psychiat., 147, 1933. 5. Frick, F. and von Angyal, L. - Ztschr. f. d. ges. Neurol. u. Psychiat, 173, 1941. 6. Jaspers, K. -- Allgemeine l'sychopathologie. Springer, Heidelberg, 1946. 7. Kampik, J. and Reiter, R. - Neue Ergehnisse aus Untersuchungen über Stumpf- und Wetterschmerzen, sowie des Phantomerlebnisses bei Amputierten. Deutsche med. Wchnschr., 242, 1948. 8. Klein - Z/tschr. f. d. ges. Neurol. u. Psychiat., 126, 1930. 9. Krat»berg - Ober das Phantomglied. Diss. Thiele, Gütersloh, 1938. 10. Rein, H. - Physiologie des Menschen. Springer, Bcrlin, 1940. 11. Skalweit, W. - Das deutsche Geshwesen, 274, 1948. 12. Stracke, J. - İber die Wahrnehmung von Korper, Raum und Bewegung durch die Haut. Nervenarzt, 433, 1947. 13. Wernicke, C. - Grundriss der Psychiatrie. G. 'Thieme, Leipzig. 14. Urban, H. J. and Sorgo, W. - Beiträge zur Behandlung des Phantomgliedschmerzes. M. Klin., 3, $\mathbf{n}^{\circ} 3,1948$. 